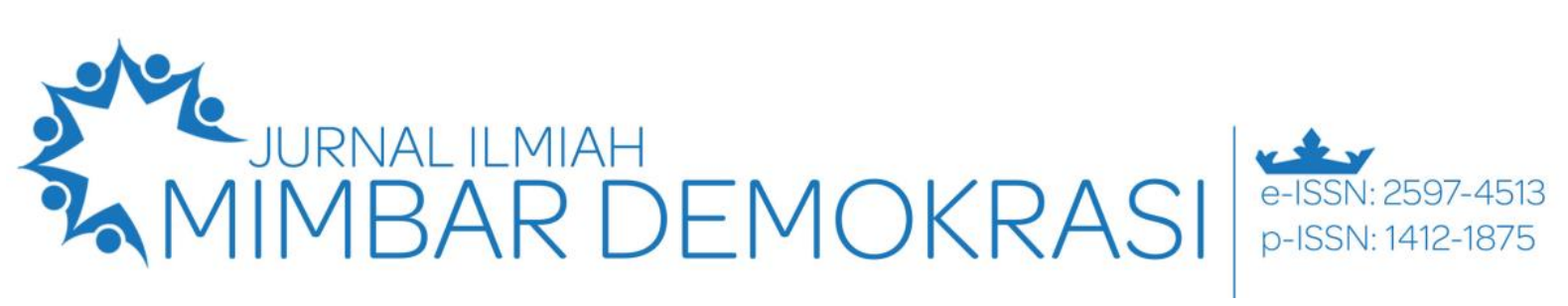

Vol. 19 No. 2 Tahun 2020 | Hal. i - ii

\title{
Editorial: Transfigurasi dan Aksentuasi Jurnal di Tahun 2020
}

Para pembaca yang budiman, Jurnal Ilmiah Mimbar Demokrasi menerbitkan artikel hasil penelitian, artikel gagasan, dan ulasan buku yang termasuk pada ruang lingkup kajian disiplin ilmu Pendidikan Pancasila dan Kewarganegaraan (PPKn). Saat ini Jurnal Ilmiah Mimbar Demokrasi secara online telah terindeks pada Google Scholar, Portal Jurnal Garuda, Crossref, Sinta dan lain sebagainya.

Pada tahun 2019, melalui Surat Keputusan No. 36/E/KPT/2019 yang dikeluarkan oleh Direktur Jenderal Penguatan Riset dan Pengembangan Kementerian Riset, Teknologi, dan Pendidikan Tinggi (Kemenristekdikti), telah menyatakan bahwa Jurnal Ilmiah Mimbar Demokrasi telah terakreditasi pada peringkat Sinta 5 mulai Volume 17 No. 12018 sampai Volume 21 No. 2 tahun 2022.

Editorial kali ini juga dimanfaatkan sebagai media informasi bahwa telah terjadi transfigurasi atau perubahan pada beberapa aspek di Jurnal Ilmiah Mimbar Demokrasi. Perubahan pertama adalah pergantian dan perubahan susunan Dewan Editor atau Editorial Boards dan Reviewers atau Mitra Bestari. Perubahan susunan dan penambahan Editor maupun Reviewer dilaksanakan dengan pertimbangan kepakaran, jejak publikasi, dan mengoptimalkan peran asosiasi profesi untuk berkontribusi pada proses penerbitan jurnal.

Selain pada susunan tersebut, perubahan juga dilakukan untuk gaya selingkung atau template jurnal dengan tujuan aksentuasi dengan kebutuhan publikasi daring. Perubahan logo jurnal dan tampilan website OJS Jurnal Ilmiah Mimbar Demokrasi juga terjadi mulai edisi ini. Pengembangan-pengembangan lain akan dilakukan secara kontinyu untuk memenuhi standard yang ditetapkan dalam rangka optimalisasi jurnal ilmiah yang dipublikasikan secara online. Demikian kami menyampaikan informasi mengenai perubahan yang terjadi pada Jurnal Ilmiah Mimbar Demokrasi.

Pada edisi kali ini, kami telah menentukan untuk menerbitkan enam buah artikel yang memenuhi standar minimal penerbitan dan memiliki dampak untuk memperkaya kajian PKn. Memperkaya pengalaman praktis PKn dengan tujuan untuk mengombinasikan fakta, nilai, dan strategi sehingga kajian PKn bisa terus terbentuk. (Levine, 2014) Kita bisa mengikuti lima prinsip untuk pengembangan Civic Studies, antara lain (1) belajar dari kolaborasi, karena kita perlu melakukannya secara interaktif dan deliberatif; (2) rendah hati, untuk mengakui keterbatasan intelektual; (3) kritik internal, agar menjadi norma komunitas untuk melakukan intellectual engagement sebagai upaya ilmiah bersama; (4) menyudahi pencarian akar permasalahan, karena lebih baik menyelesaikan yang di permukaan daripada pencarian akar masalah yang tak kunjung berhasil, dan; (5) bergandengan tangan, karena bisa jadi perubahan arah bisa terjadi dengan cepat untuk menuju arah kondisi ideal (Levine, Civic studies, 2018). Prinsip ini diadaptasi sebagai kontribusi perkembangan keilmuan.

Secara khusus, perkembangan tersebut dimulai dari: Pertama, sisi praksis yaitu inovasi strategi, model, dan temuan-temuan lainnya yang mutakhir untuk peningkatan kualitas pembelajaran PPKn. Kedua, pengembangan keilmuan PPKn dengan memperkaya pemahaman materi, cakupan, dan prospek pengembangan konten. Maka, melalui kedua faktor tersebutlah tim editor yang dibantu oleh para reviewer mengeluarkan rekomendasi untuk menerbitkan artikel terpilih tersebut.

\section{Selayang Pandang Terbitan}

Artikel pertama ditulis oleh Zulkarnain yang membahas bagaimana hegemoni negara mempengaruhi kurikulum dan praktik pendidikan kewarganegaraan di Singapura. Artikel tersebut menyimpulkan bahwa hegemoni yang dilakukan oleh pemerintah Singapura melalui kebijakan pendidikan kewarganegaraan dalam upaya menjaga status quo, tidak berhasil seperti apa yang diharapkan. maka kita dapat menyimpulkan bahwa tidak sepenuhnya benar persepsi yang mengatakan guru terhegemoni oleh negara meskipun kontrol ketat dilakukan oleh pemerintah dan begitu juga dengan guru PKn Singapura meskipun telah mendapat pelatihan.

Artikel kedua ditulis oleh Muhamad Ridwan Effendi \& Iqbal Syafrudin yang menguraikan tentang hubungan antara agama dan politik yang terjadi di DKI Jakarta dalam kerangka Pemilihan Umum Kepala Daerah (Pilkada) pada tahun 2017 lalu sebagai salah satu saluran demokrasi di Indonesia. Kajian ini 
menunjukkan bahwa proses demokrasi yang tengah berjalan telah memunculkan politik identitas agama dalam Pilkada DKI Jakarta. Penggunaan isu yang berlandaskan agama disebutkan sebagai salah satu bukti untuk menjustifikasi bahwa agama dan politik tidak dapat dilepaskan, keduanya saling mengisi satu sama lain, meskipun di antara agama dan politik memiliki ciri yang dapat membedakan keduanya.

Eliya Hakiki Nur Sugini \& Abdul Basit menyampaikan hasil penelitiannya yang bertujuan mengetahui pengaruh penggunaan media pembelajaran berbasis animasi terhadap minat belajar peserta didik kelas VII SMP Islam Alimuddin Kabupaten Probolinggo. Para penulis berharap penggunaan media pembelajaran berbasis animasi dapat membantu proses pembelajaran dan meningkatkan hasil belajar peserta didik. Hasil penelitiannya menyebutkan bahwa ada pengaruh media pembelajaran berbasis animasi terhadap minat belajar peserta didik kelas VII SMP Islam Alimuddin Kabupaten Probolinggo.

Artikel keempat merupakan karya Sri Rahayu Pudjiastuti yang bertujuan untuk memberi kontribusi pemikiran, gagasan dan strategi dan upaya dalam melakukan internalisasi nilai-nilai Pancasila untuk mencegah perkembangan paham radikal. Internalisasi nilai-nilai Pancasila dilakukan dengan cara; penguatan sistem pendidikan, peningkatan jati diri dan karakter bangsa, peningkatan komitmen pemimpin nasional, peningkatan pemahaman nilai-nilai Pancasila pada kehidupan sehari-hari melalui pendidikan, sosialisasi dan kerjasama. Penulis menyampaikan bahwa kewaspadaan masyarakat dalam menangkal penyebaran paham-paham radikal.

Yulita Pujilestari \& Afni Susila melalui artikel penelitiannya mengungkapkan media visual dapat mempermudah guru dalam memberikan materi alam pembelajaran, media visual menampilkan gambaran konkret suatu materi, media visual juga dapat memusatkan motivasi siswa dalam belajar dan siswa mudah mengerti materi pelajaran, serta merangsang keaktifan siswa dalam belajar Pendidikan Pancasila dan Kewarganegaran.

Artikel penutup edisi kali ini oleh Reja Fahlevi \& Darul Huda Mustaqim yang mengungkapkan gagasannya dalam mencari formulasi kolaborasi antara kabinet zaken dan kabinet koalisi. Setidaknya penulis menawarkan empat macam bentuk kolaborasi yang di antaranya; (1) harus ada kesepakatan mengenai platform dan agenda politik bersama di antara partai-partai yang berkoalisi, (2) adanya pembagian kekuasaan atau power sharing yang secara relatif dianggap memuaskan oleh seluruh partai mitra koalisi dan ahli, (3) perlu penegasan Presiden kepada partai politik untuk memberikan kader terbaiknya yang memiliki keahlian dibidangnya untuk duduk sebagai menteri, (4) Kabinet Zaken bisa di pilih oleh presiden melalui kontribusi partai koalisi maupun dari seleksi oleh Presiden sendiri dalam penentuan secara terbuka oleh para ahli di bidangnya masing-masing.

Demikian paparan singkat artikel yang dipublikasikan Jurnal Ilmiah Mimbar Demokrasi edisi kali ini. Semoga bisa menambah khazanah disiplin keilmuan PKn secara epistemologis yang konseptualstruktural sehingga dapat memantapkan sebagai sistem pengetahuan terpadu (Somantri \& Winataputra, 2017). Harapan kami, kontribusi pemikiran dan pengujian keilmuan bisa menjauhkan PKn dari discrepancy (penyimpangan) yang menimbulkan kabut sehingga mempersulit kita dalam melihat kelemahan-kelemahan PKn (Wahab \& Sapriya, 2011). Kita perlu berkolaborasi untuk menyibak cakrawala keilmuan PKn dengan kontribusi akademis yang bermakna. Semoga kebermaknaan itu juga terdapat di edisi kali ini.

Selamat membaca!

\section{Referensi}

Levine, P. (2014). The Case for Civic Studies. In P. Levine, K. E. Sołtan, \& B. Checkoway (Ed.), Civic Studies. Washington DC, Washington, USA: Bringing Theory to Practice.

Levine, P. (2018). Civic studies. Philosophy and Public Policy Quarterly, 32(1), 29-33.

Somantri, M. N., \& Winataputra, U. S. (2017). Disiplin Pendidikan Kewarganegaraan: Kultur Akademis dan Pedagogis. Bandung: Laboratorium PKn UPI.

Wahab, A. A., \& Sapriya. (2011). Teori dan Landasan Pendidikan Kewarganegaraan. Bandung: Alfabeta.

\section{Fauzi Abdillah}

a Managing Editor, Jurnal Ilmiah Mimbar Demokrasi

Universitas Negeri Jakarta abdillah@unj.ac.id

(D)https://orcid.org/0000-0001-6024-0610

ii Jurnal Ilmiah Mimbar Demokrasi 